\title{
On the Generation of Data in the Study of Social Interaction ${ }^{1}$
}

\author{
Kurt Kreppner ${ }^{2}$ \\ Max Planck Institute for Human Development - Berlin, Germany
}

\begin{abstract}
In this article, it is argued that the most urgent and necessary requisite for observational research is the creation of material-sensitive categories which depict details of specific situational and human conditions of exchange. It is also argued that the process of selection of single items in the stream of events is regulated by theories and interests of the observers. Without a precise set of hypotheses, no categories can be formulated. However, categories should be created in intense interaction with the observed material and new categories which can describe unexpected events during observations should be allowed. Since video-recordings guarantee a conservation of the original situation, a new and intense approach for generating categories is proposed which abandons the restrictive use of predefined categories and argues for openness and an extensive process of exchange with the material before abstractions and categories are formulated.
\end{abstract}

Key words: observational methodology; data generation; categorization of human interaction; family research.

\section{Some Personal Remarks}

This paper is a revised version of a contribution to a conference which was held in Munich, in 1983, as a preconvention workshop to the Seventh International Society for the Study of Behavioural Development [ISSBD] Conference. The workshop was entitled Observational Methodology in Social Interaction Research: Three Theoretical Approaches, Their Potential and Limits. The conveners had asked three questions: (a) What is the relationship between theory and method?, (b) What kind of methodology is needed?, and (c) What methods exist to date? During the late seventies, observational research in infancy and early childhood had just reached its first peak and, in 1983, it clearly just began to be accepted as a proper methodology for gaining information about the vividness and mutuality in early interactions between babies and caretakers. Linked to this new methodology was a growing corpus of knowledge about infants' amazing cognitive compentence and social skills.

Many psychologists, however, without experiences in infancy research, an area which had grown to a broad interdisciplinary field, remained sceptical about the usefulness of observational techniques. A multitude of scientific principles seemed to be ignored or neglected by observers, for example, the blindness of observers for expected effects. It was believed that observers may lose their objectivity dur-

1 Revised paper based on a presentation at the workshop on Observational methodology in social interaction research: Three theoretical approaches, their potential and limits, Munich, July 31, 1983. Revision written 1999/2000. My thanks go to Prof. Dora Dessen from the University of Brasilia who encouraged me to write this revision of an almost forgotten paper. Her stimulating contributions to this topic in our discussions and her never ending patience with my resistance to take up an old controversial issue again have finally lead me to this revision.

2 Correspondence concerning this article should be addressed to Kurt Kreppner. Max Planck Institute for Human Development, DahlemLentzedlee, 94, D-14195 Berlin, Germany. E.mail: kreppner@mpibberlin.mpg.de ing the process of observation and become selective by concentrating on the occurrence of expected events. However, as it soon became clear by comparing observational with strictly experimental studies, this effect was not different from the well-known experimenter effect described by Rosenthal (1966). Moreover, as the application of video guarantees preservation of the entire situation that has been observed and allows endless replications during the process of analysis, the claims that this method per se is lacking objectivity could not be maintained. Another critique against the application of observational methodology stated that trained observers would endanger objective observation. Instead, untrained and "unbiased" observers should be used. However, at a closer look, the idea of an unbiased observer apparently is a kind of irrational concept, as every human subject perceives the world with a set of expectations. Only the camera itself can produce a kind of objective protocol of an observed situation.

From a today's perspective, many of these traditional demands may appear rather desolate as the technology to conduct observations has changed and is rather different from techniques applied during the 60's and early 70's. Beginning with the mid-seventies, advanced observation always was associated with the application of video recordings of the observed situations. Observation methodology was no longer bound to observers who do direct observation and therefore have to accomplish to register what they observe on the spot and are forced to apply predefined categories. The possiblity to "freeze" the original situation, that is, to conserve the totality of aspects contained in the observed situation, has principally changed the discussion about the necessity to begin observation with a set of selected categories. Before the use of film or video, the observed situation with all its complexity was irretrievably gone when the observer and his or her notebook had left the situation. What remained were observers' tallies in the notebooks indicating the occurrence of certain behaviors. With the new technology, however, this restriction to a chosen set of categories was no longer a necessary precondition for doing proper observations. By applying video technique, the researchers 
could replicate the entire observed situation without any distortion. Furthermore, by the possibility to run a videotape many times, investigators could now concentrate on different aspects of the identical situation. Therefore, the possibility emerged to create new categories adapted to the concrete observed situations.

In many areas of infant development, observational research has won a prominent status during the last 25 years. Initial doubts to apply observation as a serious scientific method have shrunk considerably. However, in other areas of developmental psychology, such as adolescence or adulthood, let alone nondevelopmental psychology, principal arguments against the use of this method are still alive and keep researchers from applying this approach in their specific fields appropriately. In order to illuminate a little bit the background which formed the context of my original contribution, I would like to say a few words about my personal experiences with observational research when I attended the workshop in 1983.

I had been invited to this conference because I had just published some results and discussed some experiences from a longitudinal study in which we had observed a small number of families with a second child during the first two years of this second child (Kreppner, Paulsen, \& Schütze, 1981, 1982a, 1982b). One of the major goals of this study had been the linking of psychological and sociological aspects of human development by observing the continuities and changes of entire families during a period when parents have to integrate a new member, the second child, into the family and when the entire family has to adapt to the rapidly changing needs and skills of the new family member. The focus of the study was on the interplay of the second child's development with the other family members' already established interaction and communication patterns. The specific interest was on how the family integrates the new member and finds a new balance after the transition from a one child to a two child family.

While being busy to conduct observations in the homes of young families during a phase when parents run through the process of socializing and integrating a new child, our major interests and problems were not really touched by the conveners' set of questions. Neither was our main interest in linking theoretical to methodological approaches nor did we pay much attention to the adaptation of existing methodologies to our target, the family in transition. We rather felt that we were confronted with quite different problems during our intense observational work in the homes of young families. In our daily work we encountered a series of problems which seemed to belong to a different class of problems compared to those formulated by the conveners of the workshop. Our problems seemed to emerge long before any of the proposed questions could be asked. The conveners' three questions supposed a well-defined set of instruments available for categorizing or measuring the observed phenomena right at the start of any observational study. In contrast, our main problem, when watching and trying to understand what we had observed in the families and conserved on video, ap- peared to be much more fundamental, or, in other words, obviously belonged to a different class of reflections. Our problem could be described as the problem to find adequate categories which describe complex interactional situations relevant for children who grow up in their families. As our goal was to follow families for a longer period of time as they integrate their second child, the description of the various family members' actions and other members' subsequent reactions, including the specification of these actions and reactions, appeared a reasonable first step in our approach. We intended to create categories covering aspects of family life and characterizing mainly differences in family interaction patterns. In order to cover a broad spectrum of possible variations, different areas were considered such as structural and dynamic characteristics, socialization routines, and verbal and nonverbal communication aspects (see Kreppner, 1991, for details).

\section{Data Generation in Observational Research: The Use of Video Technique for Describing Complex Interactional Situations}

After nearly two decades of experience in developmental research including family studies with both infants and adolescents, some of the following arguments can now be specified much better than when the first version of this paper was written in 1983. When doing observations in families with adolescent children, difficulties in representing relevant aspects of behavior and relationship quality are different from those arising when observing families with infants. However, there are many common issues at the same time.

\section{Conservation on Video Tape}

Although, on first sight, observational conditions in infant and adolescent research may appear rather different -- unstructured natural observations in families with infants and structured, time-limited, and constellation-controlled observations in families with adolescents -- the following discussion will concentrate on problems which were identical in both areas. One of the most fundamental and recurring problems in our observational research was the choice of representation of the concrete stream of behavior. By the use of cinematic techniques, the choice of categories which can adequately describe behaviors, person characteristics or relationship quality can be delayed, as the observed situation with all its details has been conserved on tape, without any kind of abstraction. With the use of video, one of the most eminent problems in former observations, that is, the process of instant abstraction of a complex situation by the observer, could be eliminated. As Thiel (1991) has put it:

The invention of cameras and microphones has made it possible for observers to fix objects without directly involving their cognitive systems. Observers can delegate the fixation to the technical process that can perform its task iconically and nonselectively with a completeness that surpasses the observers'own capabilities. (p. 185) 
Here, the original situation can be reviewed time and again, without any limitation. This is totally different from a situation where an observer with a set of predetermined categories has to decide on the spot which of the given categories are appropriate for describing what is observed at the moment. The idea to use the camera for obtaining objectively fixed observations goes back to Arnold Gesell (1928), who was one of the first researchers in the area of human development emphasizing observation as the adequate method in infant studies. He argued for the use of cameras as objective observers:

The camera is, in a sense, mightier than the psychological eye. The living eye can see but it cannot record. Not even in the visual arcana of the most eidetic cortex can permanent immutable images be stored for retrospective reference. This is just what the camera can do for us. It can supply seriated optical records - records which do not fade with time nor warp with prejudice, but which perpetuate with impartial fidelity the configuration of the original event. (Gesell, 1928, p. 157)

Having complex situations of interaction and communication recorded on film or video, researchers are in the comfortable situation to choose among different approaches for generating appropriate categories for abstraction. Whereas predetermined categories are mandatory in case of direct observation, the choice of categories can be delayed and adapted to the specific conditions encountered during the actual observations when the total situation has been conserved on film or videotape. Here, the situation can be repeatedly observed and, for example, compared to other observed situations. The choice of categories can be exactly shaped according to the specifics of the observed situation. For example, if a mother and an infant have been observed in an interaction, exchange of gazes or rhythms of looking at each other can exactly be counted. When parents and adolescents are observed while discussing a given issue printed on a stimulus card in a structured situation, the choice of categories can be oriented toward quite different aspects of this dyadic situation such as handling the situation by interaction partners, use of linguistic style, or non-verbal framing.

\section{Choice of Categories}

The choice of categories has to be justified by the degree of proper representation of the phenomena under research. Representation of a phenomenon in a numerical relative has to be both unique and unambiguous (Suppes \& Zinnes, 1963). When this condition is not met, distortions may occur which may devalue all observational efforts. Statistical methods, as sophisticated and complex they may be, can never correct misconceptions in the process of representation and abstraction. Without thorough links from both theoretical conception and concrete observed situation to the chosen categories, abstractions may become meaningless or, even worse, be taken for reality and in turn bias further observations. Observers may ignore existent phenomena because they do not fit into their set of categories.

\section{Encounter of Barriers When Observing Real-Life Settings}

In our own research dealing with entire families and their ways to integrate and socialize new members in their natural living conditions, the choice for the observational unit appeared to be crucial for the later choice of categories. In unstructured situations of family life, conditions are very different from experimental or manipulated situations, where reality has been deliberately reduced to a number of selected variables. Representation of behavior or interaction dynamics by a set of categories becomes a critical issue in observational studies because researchers are first confronted with the richness of human behaviors in their natural context, then with the problem of selection and abstraction, and finally, when analyzing and interpreting their results, with the problem of reconstructing complex social situations by referring to frequency counts in preselected categories. Often-times, these categories are not tailored for a detailed representation of the concrete observed situation. For example, as long as categories remain on a behavioral and person-oriented basis, they cannot appropriately cover interactional dynamics. Moreover, as it is the case for research in developmental psychology, descriptive devices qualifying, at least in principle, continuity and change in interaction patterns over time are needed. Thus, the choice of categories such as intervention, support, and punishment would most likely direct the attention away from the entire situation back to only one target person. Consequently, such a shift in attention may contribute to loose the focus on family dynamics and relationship quality. However, detailed descriptions of complex relational conditions cannot be achieved easily; they can be made only after a big number of concrete interaction patterns has been observed in various situations within a family as well as across different families. Changes in communication and interaction modes are best recognized if -- with help of the videotape -- everyday life in the family has been contrasted according to different time periods and developmental stages of the child.

\section{The First Barrier an Observer Encounters}

At the beginning of an observational study, the attempt to find adequate categories for describing complex everyday interaction patterns in the family is almost always associated with a number of serious difficulties. First of all, when observations are conducted in everyday situations without any predetermined categories, a number of barriers arises and has to be overcome (Kreppner, 1982). When our team began to observe entire families without preselected categories, three barriers arose which kept us for some time from defining meaningful classifications of social interactions and recurring patterns of interaction behavior. These barriers come with observers' everyday knowledge and perception habits. During our first discussions in which we tried to find some abstractions of what we had just observed, we found ourselves trapped by focusing on what we believed was self-evident in a specific situation, or trivial, not interesting enough to be registered. 
While observing everyday life in a family, observers might be struck by the impression that nothing of any importance is happening, interactions seem to be on a normative level, action-reaction cycles seem self-evident, seemingly providing no relevant information for the observer. The first barrier which is encountered by observers who want to formulate categories relevant for the description of complex unstructured "real life" situations may be called triviality barrier.

If one continues to watch everyday interactions in a family for a longer period of time, or if one watches the recorded situation again and again on video, recurring patterns of interaction do emerge. Comparison of different situations observed in the same family, or of a similar situation observed across different families, will soon reveal family-specific communication and interaction routines. Single communication behaviors may be perceived as belonging to recurring sequences encountered at different occasions. In a lab experiment, a complex situation is always reduced to a number of variables which are to be controlled. Reduction of variation to, ideally, only one variable creates a situation easily to be observed and analyzed. However, such a situation is quite different from a situation where a family is being observed in its home, where parent and children are conducting their routine activities and where a high context validity of a developing child's environment can be found. Whereas experimenters in the lab use to manipulate subjects' environment according to their own beliefs, observers in subjects' own habitats find themselves in a quite different position: They are more drawn into the natural habitat of their subjects than this is the case with people who conduct standardized experiments. Thus, observers can be more influenced in their judgments by unexpected events on the one hand, and be exposed to the feelings of boredom when they are confronted with so-called trivial events and recurring patterns of behaviour on the other. Predefined categories are difficult to apply when the perceived stream of events carries a multitude of phenomena which seem to be relevant for the subjects' world but obviously do not fit to the basic conception of the categories at hand. Very often the barrier of triviality is encountered by observers because their attempt to describe phenomena showing up at the surface without any pregiven categories does not immediately create these relevant events that could be interpreted according to a well-established theoretical conception. Put in other words, phenomena do occur on the surface of everyday interaction rituals in a family, but do not immediately show their possible association with theory-guided categories.

Reflecting this barrier, it might be useful to refer to Kurt Lewin's (1927) basic differentiation between phenomenal and conditional genetic observational categories. He distinguished between the surface level of categories depicting the multitude of phenomena as they appear (phenomena), and an in-depth level of classifications characterizing the underlying structures or conditions which lead to or even cause the observed behaviors on the surface.

One can ask two different kinds of questions with regard to the topics of study in psychology as well as in other sciences. One can ask for the phenomenal characteristics of psychological units or events, for example, how many kinds of feelings can be qualitatively differentiated from one another or which characteristics describe an experience of a voluntary act. Aside from this are the questions asking for the why, for the cause and the effect, for the conditional-genetic interrelations. For example, one can ask: Under which conditions has been a decision made and which are the specific psychological effects which follow this decision? The depiction of phenomenal characteristics is usually characterized as "description", the depiction of causal relationships as "explanation.” (Lewin, 1927, p. 377) (Translation from German)

Thus, as a first attempt, researchers observing everyday family interactions should always try to register sequences of intrafamilial communication and action-reaction cycles. In the end, this may help find a more structured categorical framework which covers a family's specific mode to manage everyday life.

\section{The Second Barrier an Observer Encounters}

However, by trying to formulate a kind of scenario with categories describing a family-specific framework responsible for recurring patterns of interaction, researcher will encounter a new barrier: The specificity barrier. This barrier is being noticed when families are to be compared with one another. Confronted with the task to transfer interaction patterns from one family to another, the observer, unfortunately, has to realize that what seems to be a fitting set of categories depicting interaction behaviors in one family is not appropriate for what is found in another family. Each family appears as a specific unit which has its unique typical recurring interaction patterns. To find a set of overarching patterns which could be used for describing more than only one single family is apparently a complicated task. Fitting categories can best be formulated when family-specific contextual conditions are considered during the abstraction process. However, disconnected from the particular context, many of those categories begin to loose their fit when used as general and overarching classifications for a number of different families.

When we observed our families over time, we could overcome this specificity barrier by systematically comparing families in similar situations. This means that families were likened when they had to accomplish analogous tasks and to resolve common problems in their everyday lives while socializing their children, such as changing diapers or feeding during infancy, conveying rules and regulations during the second and third year, or, later, during the child's adolescence, negotiating increasing demands for more autonomy and responsibilites. This concept of analogous tasks all families have to accomplish may overcome this barrier.

\section{The Third Barrier an Observer Encounters}

Under a developmental perspective, the third barrier is being encountered even when the second one has been overcome. The question remains how one might assess the relevance of 
an observed and categorized behavior for future development? Here, at first sight, no immediate medication seems at hand, even when the material is intensely being screened. Can we conclude from certain sets of interaction patterns that they will push a child in the family in the one or the other direction of his or her developmental pathway? In contrast to the time of the workshop, the early 80's, we have today a broader knowledge base available when we try to tackle the problem of developmental relevance concerning behavior patterns or relationship quality in the family. Newer research in families with both small and adolescent children has amply shown that, for example, relationship quality between parents is highly relevant for the children's successful or unsuccessful mastering of developmental passages. As Erel and Burman (1995) have revealed, a strong relationship between the children's development and the quality of the marital relationship was found in a number of studies with children's ages ranging from infancy to adolescence. Moreover, a study focusing on the quality of sibling interactions (Erel, Margolin, \& John, 1998) found that the establishment of the quality of sibling interactions in a family is associated with the quality in both marital and parent-child relationship. Whereas during the early years, researchers looked intensely for single variables to be responsible for different pathways during individual development, results from a number of more recent observational studies indicate that not single variables but accumulations of variables and more complex relational conditions seem to be responsible for children's developmental processes. As far as results are now available, it appears that, aside from temperament and genetic differences, no single components of interaction patterns but aggregations of various components might be relevant for differences in the child's course of development. When, for example, parents have frequent arguments with one another and are unable to find a common solution for a problem, they obviously do neglect each other, and do not pay enough attention to the partner's arguments. In this climate, children grow up in a kind of communication culture which is apparently not fostering children who demand more autonomy and try to negotiate changes in personal responsibilities with their parents. However, these demands and negotiations are essential for mastering a successful transition from childhood to adolescence. Moreover, studies focusing on divorced families have also found that not one single component but accumulations of a number of conditions covering both economic and interactional aspects may be responsible for disadvantages for children coming from broken homes (Hetherington, Bridges, \& Insabella, 1998).

Thus, summing up, observers watching family interactions and looking for aspects that are relevant for future development frequently may encounter what we have called the barrier of irrelevance. From a today's point of view, conditions to overcome even this barrier seem a little bit more promising than two decades ago. Aspects like relationship quality or mutuality, as complex as they may appear, are good candidates for abstractions which carry developmental relevance. Under an observation-methodological perspective it seems well possible to assess the quality of a relation- ship in any act of communication. However, looking for relational quality in an everyday interaction, one should be aware of the fact that in our Western culture, in our usual way of classifying, we tend to focus on persons and their actions, their intentions and motives, not on relationships and their qualities. Moreover, even if we try to concentrate on the description of relationships, not persons, it is sometimes hard to discuss with others the various qualifications of a relationship, because we are just not used to appropriately specify relationships by common words or concepts as this is the case when we talk about persons.

\section{On the Generation of Relational Data I: Some Practical, Theoretical, and Methodological Issues}

\section{Reliability}

In early infancy research, immense amounts of data were generated by registering highly visible behaviors like moving the body, gazing or grasping. However, these behavioral aspects could seldom be linked to some higher-order outcome variables like intelligence or social skill of the child in later development. The developmental validity of single behaviors could not be established. A criterion widely used for assessing the quality of classifications aside from any validation was, and still is, the degree of agreement between two observers who watch the same situation and use predefined categories, the so-called interrater reliability. This procedure is a necessary step to guarantee at least a minimum degree of observers' consent concerning the plausible use of a set of predefined categories. However, a high degree of reliability does not guarantee that the given classification represents an adequate abstraction of a relevant piece of reality. With entire situations preserved on video tape, a number of alternative procedures is possible to gain indicators for the plausibility of a representation.

A selection of categories based only on the criterion of interrater reliability is in danger to choose those phenomena as being relevant. They may be distinguished easily by some observers but do not really represent aspects that are interesting for a specific theory-oriented question. Decisions for proper abstractions from reality, that is, meaningful representations of observed situations, might be possible only after intense screening of the material preserved on video tape, sometimes only after extensive comparative analyses of longitudinal observations. The formation of adequate categories should be oriented toward capturing the variety as well as the specificity, that is, the entire richness of phenomena observed in a situation. With such a perspective, it should be clear that the criterion to select categories cannot only be aligned with the easiness of two raters to agree in the first place, though this condition also has to be met in the end. If, for example, the focus of observation has been on interaction rituals shown by the two parents in a family, a premature selection of categories according to the criterion of high interrater reliability increases the danger that only those abstractions of this complex pattern survive, describing simple 
-- but perhaps irrelevant -- behaviors. Therefore, other classifications [are dismissed] which may cover a more sophisticated and relationship-oriented conceptualization but would need some sensitive elaboration of relevant details for the raters [are dismissed]. In this case, reliability oriented category selection undoubtedly leads to the reduction of a complex reality, to a set of perhaps only very trivial behaviors which do not mirror those aspects which had been the study's initial targets. Low interrater reliabilities can be discussed and the choice of categories can be better adapted to what observers can discriminate after a process of sensitive instruction. Sometimes, it is not easy to decide whether categories are well chosen and raters ignorant, or categories are badly chosen, without clear differential guidelines, and raters are competent but cannot get along with ambiguous categories. Thus, the choice of categories should always be a long process of interaction between researchers who did conceptualize the study and those who analyze the observations. With the possibility to replicate the observed situation, such an extended process now becomes possible.

\section{Concepts and Categories}

In developmental psychology, infants were long believed to be passive, only reacting to stimulations. Thus, when infants were observed even in interactions with their mothers, observers categorized behaviors of babies that fitted well to their expectations: Reactions to mothers' stimulations. It needed a new concept of babies' activities (Bell, 1968) to construct categories which could register babies ‘ own activities directed to stimulate their mothers (e.g., Sorce, Emde, Campos, \& Klinnert, 1985; Tronick, 1989; Tronick \& Cohn, 1989). As in the case of early infant development, a growing corpus of data collected in various studies finally discovered infants' very early sensitivity with regard to complex social relationships and communication contexts (see Saarni, Mumme, \& Campos, 1998). Researchers might have started their observations with concepts that were oriented toward mothers and how they were influencing behavior patterns in their children, but the openness for unexpected experiences during observations revealed infants' capabilities and activities. Thus, a new theory about infant competence could finally create a set of new categories which do describe complex mother-infant interactions. This openness for new aspects and the deliberate delay of applying predefined categories during observations has been emphasized, for example, by infancy researchers such as Richards and Bernal (1972) and Trevarthen (1977) who describe their experiences of their first observations:

Our recording of categories grew out of our observations rather than being imposed on them by some pre-determined position. At first we watched without making any attempt to record. Later we began to note features of behaviour that recurred regularly. (Richards \& Bernal, 1972, p. 181)

I have avoided quantitative analyses until the patterns of action became clear. (Trevarthen, 1977, p. 9)
Historically, this shift from the concept of a passive to an active and competent infant began during the early seventies, the time when the above mentioned openness in observational research emerged. Biologists and ethologists began to observe mother-child interactions under more dynamic and holistic aspects. They constructed a whole new framework of concepts and categories focusing on species-specific abilities like intention or intersubjectivity. Examples for such an extension of the categories to describe interactions between parent and children are the registration of greeting behavior between mothers and their very young infants (Papoušek \& Papoušek, 1977), or steps in the dance to find a common rhythm (Stern, 1977). Cowan and Cowan (1987) proposed an even more complex interactional concept to be observed in the interactions between the parents after the arrival of their first child, the parental gavotte, a push and pull pattern characterizing the young mothers' and fathers' struggle to get along with the new family member and with each other. Another example for such a shift to more complex descriptive categories of interactions can be found in the work of Patterson (1979, 1986; Patterson \& Capaldi, 1991) who had started from a very distinctive behavioral framework and microanalyses of single behaviors and ended up studying more molar units for the description of interaction and transmission processes in the family. Mutuality, disruption, correction of misunderstanding, or disregarding the other' s signals were new concepts oriented toward a more holistic concept of human interaction and communication.

\section{Danger of Reification}

Without a thorough link between concept and category as well as without categories' adaptation to the concrete observed situations, the formalized or even standardized use of classifications may become a perversion of the initial intention of a meaningful abstraction and a danger for future explorative observations. The "reification" of categories may blind an observer for new phenomena which might show up during observation but are ignored because of the fact that they do not fit into the set of selected categories. Dewey (1922) is one of the few who related to the difficulties to reify the categories that once have been deliberately chosen to classify human actions and reactions. Reification means that the functional aspect of describing complex phenomena by doing some abstractions from the concrete is no longer kept in mind. As a consequence, abstractions to form categories are no longer seen as deliberate choices and attempts to represent reality, but rather as given and the abstract classification becomes itself a tool for explaining reality.

To classify is, indeed, as useful as it is natural. The indefinite multitude of particular and changing events is met by the mind with acts of defining, inventorying and listing, reducing to common heads and tying up in bunches. But these acts like other intelligent acts are performed for a purpose, and the accomplishment of purpose is their only justification. Speaking generally, the purpose is to facititate our dealings with unique individuals and changing events. When we assume that our clefts 
and bunches represent fixed separations and collections in rerum natura, we obstruct rather than aid our transactions with things. We are guilty of a presumption which nature promptly punishes. We are rendered incompetent to deal effectively with the delicacies and novelties of nature and life. Our thought is hard where facts are mobile; bunched and chunky where events are fluid, dissolving. (Dewey, 1922, pp. 131-132)

This malfunctioning approach to abstractions, illuminated by Dewey in his example of reification of instincts, sometimes seems to have survived in today's discussions about observational methodology. In order to avoid the danger of these kinds of reifications, open observation of behavior in context may provide some relief, particularly when observation is aiming not just at the description of a surface phenomenon but rather at the detection of recurring patterns and in-depth structures of behaviors.

\section{On the Generation of Relational Data II: Proposals for Extended Applications}

\section{New Categories for Complex Relationship Patterns in Triadic Constellations}

Observational data describing two interacting persons need categories which cover the dynamics between these two persons. Historically, Sackett's (1979) lag analysis and Gottman's (1979) time series analyses including aspects of information theory (Gottman \& Bakeman, 1979) mark the initial attempts to gain insight into dynamic processes during interactions. However, these analyses were mostly restricted to dyadic interactions. Families are constituted by more than two, at least by three persons. Two parents and a child form a triadic constellation with two intergenerational parent-child relationships and, in addition, the marital relationship between the parents. Thus, triadic situations with both parents and a child are assumed to represent a typical interaction situation in a family. Intergenerational and interparental transmission takes place simultaneously and children's participation in the parent-parent communication may reveal their specific experiences within the complex relational network in the family. These experiences cannot be properly depicted by observations of family dyads (Cowan \& McHale, 1996).

Categorizations of higher-order relational behavior may be very promising, if, and only if, those aspects are described covering the real higher-order relational effect, and not just replicating single or dyadic aspects of communication. In our own attempt to develop a triadic scoring system (Ullrich \& Kreppner, 1999), we did not focus on a comparison on dyadic with triadic constellations, as this has been emphasized, for example, in studies conducted by Deal and his coworkers (Deal, Hagan, Bass, Hetherington, \& Clingempeel, 1999). Instead, we tried to elaborate the unique dynamics unfolding only in a triadic constellation and not to be seen in dyadic constellations. The child cannot see the relationship between the parents in life performance, when he or she is in a dyadic situation with one parent. In a triad, the child may particularly experience such complex behavior patterns as integration or exclusion of a third person, loyality or coalitions, competition or jealousy. When both parents are present in a triad, the child can observe the dynamics of parental relationship, e.g., how mother and father deal with opposite opinions etc. The child reacts to an interparental communication which can also only be seen by the child in a triadic constellation and never in a mother-child or a father-child dyad. This kind of specific dynamics in a triad, which is largely different from what unfolds in a dyadic relationship, has been explained under a more formalistic perspective by Kelley and Thibaut (1978), for example, and further elaborated as being important for individual developmental pathways by McHale and Rasmussen (1998). For instance, increased anxiousness of 3-4 year-old children was predicted by parent's increased distancing behavior when the child was 11 months-old. By the same token, aggression was higher in children when aggressive-competitive behavior and low harmony was found in the mother-father-child triad. New formal aspects of the dynamics in a triad were observed in newer studies and reported to be important when they focused on the dynamics in the triadic constellation (Jory, Rainbold, Karns, Freeborn, \& Greer, 1996) such as specific directed exchanges (e.g., from mother to child to father or from child to mother to father), or exclusion rituals (e.g., one member is being treated by the other two as an outsider (Bowen, 1976). Another new approach can be seen in McHale's (1995) attempt to score communication dynamics in triads. He introduced variables such as child orientation versus parent orientation, or mutual support, or aggressive intervention, excluding one member.

In sum, although researchers are confronted with an immense complexity in a triad, intense observation of this constellation has contributed to create a number of new categories which now describe interactive conditions much more directly than this is the case when only single behaviors serve as the basis for categorizations.

\section{Productive and Reproductive Approaches in Observational Research}

Since observers use film or video technique to preserve what they have observed, quite innovative approaches for generating categories in order to produce data have become possible. These categories are rather different from those which were constructed when data had to be produced on the spot during observation. Thiel (1991) has introduced the notion of reproductive or productive approach. A reproductive approach makes extensive use of the fact that the total situation is fixed on videotape and can be reconstructed by carefully repeated viewing of the tape, by slow-motion analysis and transcription of verbal utterances. This recursive-reflective process begins an interpretation of the observed material (a social situation with more or less complex interaction and communication maneuvers of the observed participants) which, after some cross comparisons with other situations, leads to an in-depth-analysis of observed phenomena. This 
reproductive approach may end in an interpretation of the in-depth structure of a set of recurring behavior patterns as this has been proposed by Kurt Lewin (1927). Such a procedure may lead to a new understanding of various forms and sequences of behavior patterns that occur in a certain situation. Here, the focus has been shifted from the description of single behavior elements to the acquisition of knowledge about processes which may generate these single behaviors.

A precise transcription of a scene may foster the reproductive approach. It demands a highly intense reconstruction of the interplay of verbal behaviors, gestures, facial expressions and body movements which in turn supports the recursive-reflective process. In order to produce a coherent interpretation of the scene, components that were previously either ignored or considered trivial may be included. The aim of this procedure, then, is not the accumulation of more and more behavior sequences, but the understanding of those underlying processes which lead to the observed behavior sequences.

Another way to deal with observational material is possible when modern video technique is used. It is the productive approach. It applies advanced cinematographic techniques and aims at the revelation of new aspects which are possibly blurred or even hidden in a single situation and may emerge only when, for example, materials are linked together on a new tape showing the same person in different situations, and perhaps even in different developmental periods. This intentional condensation of a person's behaviors in different situations and developmental periods may generate new insights about the stability of so-called typical recurring patterns over time. Thus, the new editing of video material coming from different observations may help produce overarching formats depicting similar behaviors in a person and his or her modes to interact with other persons. Moreover, this technique may also contribute to create new typifications of observed behaviors. According to Gesell (1928, 1935),

\begin{abstract}
The photographic documentation must be conceived in such manner as to preserve significant sequences. Growth is elusive because it is ever changing. The process of change is so subtle that it cannot be grasped by instantaneous judgment. Therefore we may turn to this third eye, the recording eye of the camera, to catch what eludes; to bring past, present, and future together in close compass. The function of the camera is to dissolve the encumbrance of chronological age so that the sequences of growth may be glimpsed in close, spatial juxtaposition without the deteriorating tedium of long lapse of time. With these underlying principles in mind we have undertaken to develop certain possibilities of photography in the genetic study of infancy. (Gesell, 1928, pp. 56-57)
\end{abstract}

The advantage of using montage techniques for the creation of categories is still widely ignored, even though it is obvious that this approach could be very helpful for the comparison of longitudinal recordings. It could open a new window in the search for indicators relevant in individual developmental processes. Unfortunately, many contemporary re- searchers apparently seem to categorize what they have observed and preserved instantly from tape as if they had to do the classification during the observation, once and forever. Observation techniques are -- even after over seventy years of available filmrecording techniques -- under debate in a way as if only the method of direct observation existed. Our long history of using film techniques for exploring development, manifest, for example, in the writings of Gesell or Lewin, seems almost forgotten.

\section{Creation of New Classes of Variables Describing Interactions and Relationships}

Whereas even today most studies applying observational methods are still collecting data just about single behaviors, modern observation techniques including advanced editing devices could offer richer approaches to data collection and open a wider range of opportunities to analyze complex relationship patterns or developmental changes. Of course, aspects like mutuality, flow of communication, and regulation of emotions in a relationship would need an additional shift in observers' attention from single behaviors to interactions as well as in researchers' designs to create complex situations in which subjects are observed. By the same token would these relationship-oriented concepts also call for new and more complex settings in which observations should be conducted. By generating new classes of variables, we might hopefully come a step closer to Lewin's (1927) demand for revealing conditional-genetic connections between behavior patterns visible on the surface and their underlying basic relational dynamics responsible for their repeated occurrence. These variables should be able to depict more complex interactional phenomena as, for example, the establishment of common meaning in a family by guidance, warmth, and order. However, dealing with a concept characterizing the quality of meaninful exchange in a relationship would need the addition of a number of references either to subjects' internal representations or to other observable phenomena because, for instance, the establishment of common meaning in a relationship cannot be observed directly. What can be observed, however, is the exchange of emotions, degree of sensitive adaptation to the other's intentions, ability to correct misunderstandings and the like. For example, Spitz (1964) has emphasized in his work the role of affect for the construction of meaning in the mother-infant relationship. The consumption of meaning is connected with a positive affect, the positive ending in an action cycle in the dialogue. If this cycle is interrupted, and the meaning cannot be consumed, then, in Spitz's terms, the dialogue between mother and infant "derails." By the same token, Sroufe (1996) has underlined the role of emotion as an organizing principle from the construction of meaning in early childhood. As many observational studies in developmental research still continue to collect only disconnected behavioral units, a more intense attempt to create new classes of variables mirroring the dynamics of emotional and cognitive exchanges in a relationship could be very helpful to track down the alternate 
in-depth structures of the two developmental pathways leading to an individual's capacity to establish either well-functioning or malfunctioning relationships.

\section{Concluding Remarks}

This article is the revision of a paper written about two decades ago for the discussion of problems associated with the application of observational methods. Since then, a long period of time has elapsed and immense technical progress has changed the conditions for observational research dramatically. The reflection of continuities and changes during this long period when reading the old text has produced three major results. First, the method of observation indeed has won more acceptance and reputation compared to the past, particularly in infancy research. Second, advanced observation techniques are used by more and more researchers. However, paradoxically enough, analyses and evaluations of the observed situations frozen on videotape are still carried out in a way as if they were under the restrictions of direct observation without conservation. Third, another result of this review is the fact that most of the fundamental questions associated with the method of observation have not been further elaborated during the last two decades, although this method has amply been applied, for example, in infancy research. I have tried to touch some of the questions such as how to find proper representations, how to overcome basic barriers which may hinder observers, and how reproductive as well as productive approaches may be used to handle observational material. The breaking ideas about possible gains when using observation as a method, as discussed a long time ago by Lewin or by Gesell, seem almost to be lost. Many of the questions asked and also answers given by these researchers could perhaps be more present in contemporary methodological discussions if the richer use of observational aids such as video technique and eletronic processing, were seriously considered. Today, with the new possibilities to work with video material in a way we are used to work with our texts on the computer, we have to accomplish the task of driving observational methodology to a point where something like in-depth structures producing surface phenomenon labelled by Lewin as the conditional-genetic connections, could be revealed, or where, with the help of Gesell's ideas about using montage techniques, new insights into the process of development could be created. Reviewing observational studies applying advanced video techniques we still find too many traditional singlevariable designs and linear cause and effect analyses in our field. The richness of human interaction in all its complexity might have been conserved on many tapes, but only a new way to analyze them using new concepts might bring us a step further.

\section{References}

Bell, R. Q. (1968). A reinterpretation of the direction of effects in studies of socialization. Psychological Review, 75, 81-95.
Bowen, M. (1976). Theory on practice of psychotherapy. In P. J. Guerin (Ed.), Family therapy (pp. 337-388). New York: Gardner Press.

Cowan, C. P., \& Cowan, P. A. (1987). Men's involvement in parenthood: Identifying the antecedents and understanding the barriers. In P. W. Berman \& F. A. Pedersen (Eds.), Men's transition to parenthood (pp. 145-174). Hillsdale, NJ: Lawrence Erlbaum.

Cowan, P. A., \& Mc Hale, J. P. (1996). Coparenting in a family context: Emerging achievements, current dilemmas, and future directions. In W. Damon (Series Ed.), J. P. McHale, \& P. A. Cowan (Vol. Eds.), New Directions for Child Development: Vol. 74. Understanding how family-level dynamics affect children's development: Studies of two-parent families (pp.93106). San Francisco: Jossey Bass.

Deal, J. E., Hagan, M. S., Bass, B., Hetherington, E. M., \& Clingempeel, G. (1999). Marital interaction in dyadic and triadic contexts: Continuities and discontinuities. Family Process, 38, 105-115.

Dewey, J. (1922). Human nature and conduct. An introduction to social psychology. New York: Henry Holt and Company.

Erel, O., \& Burman, B. (1995). Interrelatedness of marital and parent-child relations: A meta-analytic review. Psychological Bulletin, 118, 108-132.

Erel, O., Margolin, G., \& John, R. S. (1998). Observed sibling interaction: Links with the marital and the mother-child relationship. Developmental Psychology, 34, 288-298.

Gesell, A. (1928). Infancy and human growth. New York: MacMillan Company.

Gesell, A. (1935). Cinemanalysis: A method of behavior study. Journal of Genetic Psychology, 47, 3-16.

Gottman, J. M. (1979). Time-series analysis of continuous data in dyads. In M. E. Lamb, S. J. Suomi, \& G. R. Stephenson (Eds.), Social interaction analysis (pp. 207-226). Madison: University of Wisconsin Press.

Gottman, J. M., \& Bakeman, R. (1979). The sequential analysis of observational data. In M. E. Lamb, S. J. Suomi, \& G. R. Stephenson (Eds.), Social interaction analysis (pp. 185-206). Madison: University of Wisconsin Press.

Hetherington, E. M., Bridges, M., \& Insabella, G. M. (1998). What matters? What does not? Five perspectives on the association between marital transitions and children's adjustment. American Psychologist, 53, 167-184.

Jory, B., Rainbolt, E., Karns, J. T., Freeborn, A., \& Greer, C. V. (1996). Communication patterns and alliances between parents and adolescents during a structured problem-solving task. Journal of Adolescence, 19, 339-346.

Kelley, H. H., \& Thibaut, J. W. (1978). Interpersonal relations. A theory of interdependence. New York: Wiley.

Kreppner, K. (1982). Zur interpretation von alltagshandeln in der familie: Drei barrieren vor dem erkennen? [On the interpretation of everyday behavior in the family: Three barriers before knowledge?]. Contribution to the discussion group "Experiences with non-standardized research methods" at the 33th Conference of the German Society for Psychology, Mainz, Germany.

Kreppner, K. (1991). Observation and the longitudinal approach in infancy research. In M. Lamb \& H. Keller (Eds.), Infant 
development: Perspectives from German-speaking countries (pp. 151-178). Hillsdale, NJ: Lawrence Erlbaum.

Kreppner, K., Paulsen, S., \& Schütze, Y. (1981). Familiale dynamik und sozialisatorische interaktion nach der geburt des zweiten kindes [Family dynamics and socialisation interaction after birth of the second child]. Zeitschrift für Sozialisationsforschung und Erziehungsstile, 1, 291-297.

Kreppner, K., Paulsen, S., \& Schütze, Y. (1982a). Infant and family development: From triads to tetrads. Human Development, 25, 373-391.

Kreppner, K., Paulsen, S., \& Schütze, Y. (1982b). Kindliche entwicklung und familienstruktur [Child development and family structure]. Zeitschrift für Pädagogik, 28, 221-244.

Lewin, K. (1927). Gesetz und experiment in der Psychologie [Law and experiment in psychology]. Symposion, 1, 375-421.

McHale, J. P. (1995). Coparenting and triadic interactions during infancy: The roles of marital distress and child gender. Developmental Psychology, 31, 985-996.

McHale, J. P., \& Rasmussen, J. L. (1998). Coparental and family group-level dynamics during infancy: Early family precursors of child and family functioning during preschool. Development and Psychopathology, 10, 39-59.

Papoušek, H., \& Papoušek, M. (1977). Mothering and the cognitive head-start: Psychobiological considerations. In H. R. Schaffer (Ed.), Studies in mother-infant interaction (pp. 6385). New York: Academic Press.

Patterson, G. R. (1979). A performance theory for coercive family interaction. In R. B. Cairns (Ed.), The analysis of social interaction (pp. 119-162). Hillsdale, NJ: Erlbaum.

Patterson, G. R. (1986). Performance models for antisocial boys. American Psychologist, 41, 432-444.

Patterson, G. R., \& Capaldi, D. M. (1991). Antisocial parents: Unskilled and vulnerable. In P. A. Cowan \& M. Hetherington (Eds.), Family transitions (pp. 195-218). Hillsdale, NJ: Lawrence Erlbaum.

Richards, M. P. M., \& Bernal, J. F. (1972). An observational study of mother-infant interaction. In N. Blurton-Jones (Ed.), Ethological studies of child behaviour (pp. 175-197). Cambridge: Cambridge University Press.

Rosenthal, R. (1966). Experimenter effects in behavioral research. New York: Appleton Century Crofts.

Saarni, C., Mumme, D. L., \& Campos, J. (1998). Emotional development: Action, communication, and understanding. In W.
Damon (Series Ed.) \& N. Eisenberg (Vol. Ed.), Handbook of Child Psychology: Vol. 3. Social, emotional, and personality development (5th ed., pp. 237-309). New York: Wiley.

Sackett, G. P. (1979). The lag sequential analysis of contingency and cyclicity in behavioral interaction research. In J. D. Osofsky (Ed.), Handbook of infant development (pp. 623-649). New York: Wiley.

Sorce, J. F., Emde, R. N., Campos, J., \& Klinnert, M. D. (1985). Maternal emotional signaling: Its effect on the visual cliff behavior of 1-year-olds. Developmental Psychology, 21, 195-200.

Spitz, R. (1964). The derailment of dialogue: Stimulus overload, action cycles, and the completion gradient. Journal of the American Psychoanalytic Association, 12, 752-770.

Sroufe, L. A. (1996). Emotional development. The organization of emotional life in the early years. New York: Cambridge University Press.

Stern, D. N. (1977). The first relationship. Infant and mother. London: Open Books.

Suppes, P., \& Zinnes, J. L. (1963). Basic measurement theory. In R. D. Luce, R. R. Bush, \& E. Galanter (Eds.), Handbook of mathematical psychology (pp. 1-16). New York: Wiley.

Thiel, T. (1991). Videotechnique and science: Methodological considerations. In M. Lamb \& H. Keller (Eds.), Infant development: Perspectives from German-speaking countries (pp. 179195). Hillsdale, NJ: Lawrence Erlbaum.

Trevarthen, C. (1977, October). Instincts for human understanding and for cultural cooperation: Their development in infancy. Paper presented at the Werner-Reimer-Stiftung Symposium on Human Ethology, Bad Homburg, Germany.

Tronick, E. Z. (1989). Emotions and emotional communication in infants. American Psychologist, 44, 112-119.

Tronick, E. Z., \& Cohn, J. (1989). Infant-mother face-to-face interaction: Age and gender differences in coordination and the occurrence of miscoordination. Child Development, 60, 85-91.

Ullrich, M., \& Kreppner, K. (1999, September). Kommunikation in eltern-kind triaden mit jugendlichen: Entwicklung eines kategoriensystems [Communication in parent-child triads with adolescents. Development of a category system]. Paper presented at the fourteenth Meeting of the Division of Developmental Psychology in the German Psychological Society, Fribourg, Schwitzerland. 